\title{
Investigation of Diethyl Hexyl Phthalate Migration from Poly(Vinyl Chloride) Serum Bags
}

\author{
Dalila Ikermoud, Naima Belhaneche-Bensemra, and Hicham Benaissa
}

\begin{abstract}
Plasticizers are used to make Poly (Vinyl Chloride) (PVC) flexible so it can be used in different areas such as intravenous solution containers. Plasticizers can migrate from PVC over time because of contact with these solutions; this phenomenon creates gaps in the polymer structure and causes the migration of other additives. This paper discusses the specific migration of di-2-ethyl hexyl phthalate (DEHP) from plasticized poly (vinyl chloride) (PVC) into 5\% glucose solution, although studying the possibility of migration of other components. For this purpose, the bags were stored in real conditions by respecting temperatures $\left(20 \pm 2^{\circ} \mathrm{C}\right)$ and time of conservation (18 months). Samples were taken off every 3 months to be analyzed. The Fourier transform infrared spectroscopy was used to investigate the migration phenomena, the atomic absorption spectrometry was used to follow the migration's evolution of metals from plastic bags and the gas chromatography coupled with mass spectrometry was used for the determination of DEHP migration. The results obtained by the three techniques showed the migration of the serum bags additives such as DEHP in the glucose solution. This migration depends on time of contact.
\end{abstract}

Keywords-DEHP, migration, plasticizer, PVC, serum bag.

\section{INTRODUCTION}

Polyvinylchloride is an inexpensive commodity plastic material that is used in a wide variety of domestic and industrial applications. Knowing that practically all plastics are composed of polymerized organic substance, PVC is made up of polymerized vinyl chloride, together with one or more additives that modify the characteristics of the polymer in order to optimize its suitability for a given application or process. PVC is used in some situations with minimal additives; in this case, it is used as rigid and hard material. However, the best performance can be achieved when the material is made more flexible and softer. For this purpose, an additive described as a plasticizer is used, and the resulting plasticized PVC finds extensive applications because of its excellent and varied properties.

The flexible PVC is used as pharmaceutical packaging materials witch offer several advantages: extended storage time, efficient transportation for product freshness and low price, but the interaction between the package and the product can affect the quality of the content. This interaction can be caused by the migration of the plasticizer into liquid, which is attributed to two mechanisms. The extraction of the plasticizer can occur in the first case when the molecular size of the extractant is too large to enter the PVC polymer structure;

Manuscript received May 20, 2021; revised November 27, 202.

D. Ikermoud is with the Centre de Recherche en Technologie des Semi-conducteurs pour l'Energétique (CRTSE), Algiers, ALGERIA. (e-mail: ikermoud.dalila@gmail.com).

$N$. Belhaneche-Bensemra is with Laboratoire des Sciences et Techniques de l'Environnement, Ecole Nationale Polytechnique (ENP), Algiers, ALGERIA. (e-mail: naima.belhaneche@g.enp.edu.dz).

H. Benaissa is with the Central Forensic Laboratory of Algiers, Algiers, ALGERIA. (e-mail: hbenaissa66@gmail.com)

Digital Object Identifier (DOI): 10.53907/enpesj.v1i2.48 therefore, the migration can occur only by the plasticizer molecules diffusing to the surface of the PVC and then dissolving into the liquid. The second case, when the molecular size of the extractant liquid is sufficiently small to enter into the PVC polymer structure; the major mechanism for this extraction is that the extractant diffuses into the plasticized PVC, dissolves the plasticizers then diffuses together with the dissolved plasticizers out to the surface of the PVC [1].

Di (2-ethylhexyl) phthalate, also known as di-octyl phthalate (DOP), universally referred to as DEHP is a colorless with almost no odors, oily liquid used to increase flexibility of PVC. DEHP was first produced in commercial quantities in Japan around 1933 and in the United States of America in 1939; it is found in a wide array of products including medical devices. Virtually all glucose bags made from PVC use this plasticizer, which is the long chain phthalate ester examined most extensively. There are a large number of reviews of the toxicological profile of DEHP; since February 2015 di(2ethylhexyl) phthalate may only be sold and used in the European Union after authorization for a particular use [2-4].

People as well as animals can be exposed to the phthalate compounds through ingestion, inhalation or dermal exposure and it has a harmful effect on their health. The effects of di-(2ethylhexyl) phthalate and its metabolites on fatty acid homeostasis regulating proteins in cells were proved in many investigations. To study the effect of DEHP on testicular mitochondrial viability: male albino rats were received di-ethyl hexyl phthalate (DEHP) $(500 \mathrm{mg} / \mathrm{kg} /$ day orally). The administration of DEHP increases the lipid peroxidation and decreases considerably the testicular mitochondrial viability. DEHP induces a severe testicular oxidative damage and DNA (Deoxyribonucleic acid) fragmentation. Other studies examined the metabolite profile in plasma and liver of rats exposed to DEHP and showed induction of cyanide-insensitive palmitoyl-coenzyme an oxidation per gram of liver was greater in males than in females. Liver weight was significantly increased in the DEHP-treated groups compared to that of controls. Immunohistochemical analysis demonstrated that DEHP caused strong staining of proliferating cell nuclear 
antigen after exposure, suggestive of hepatocyte proliferation [5-8].

In rats, after 10 days systemic administration of DEHP, a study conducted to investigate the hepatic toxicity of sub-acute DEHP exposure at different selenium (Se) status demonstrated that DEHP exposure increased oxidative stress by disturbing the antioxidant balance in the hepatocytes [9]. The male reproductive toxicity of DEHP is well established and has been studied in many species including mice, rats, hamsters, ferrets, and non-human primates. This toxicity is depending on the age of animals, the doses, dosing duration and endpoints included. It has been shown that oral treatment with DEHP causes decreased weights of male, reduced fertility, reproductive organs, and histopathological changes in the testis of juvenile and adult rats. Testes of the Big Blue ${ }^{\circledR}$ transgenic mice were treated every day for a month with DEHP indicated an approximately 3-fold increase in genomic DNA mutation frequency compared with controls. These results unveiled the hazardous effects of direct low-level exposure of DEHP on ability of spermatozoa fertilization as well as embryonic development, and proved that in vivo DEHP exposure posed mutagenic hazards in the reproductive organ, which are of great concern to human male reproductive health $[10,11]$.

For the general adult human population, exposures to DEHP are estimated to be $3-30 \mu \mathrm{g} / \mathrm{kg} /$ day. This plasticizer is suspected to induce anti-androgenic effects in men via its metabolite mono (2-ethylhexyl) phthalate (MEHP). However, there isn't enough information on the kinetic behavior of DEHP and its metabolites in humans. A comparative human intravenous and oral administration of DEHP in recent study likewise yielded a high proportion of glucuronized metabolites of between $77 \%$ and $84 \%$, after oral administration; this value was $80 \%$ in intravenous administration $[4,12,13]$.

The noticed toxicity of DEHP and existence of alternatives to many DEHP-containing PVC medical devices presents a compelling argument for moving assertively, but carefully, to the substitution of other materials for PVC in medical devices. The substitution of other materials for PVC or phthalate plasticizer would have an added people and community health benefit of reducing population exposures to DEHP [14-17].

The aim of the present work is to investigate the specific migration of DEHP from plasticized PVC into 5\% glucose solution and to estimate this rate of loss, although studying the possibility of other component's migration by using various analytical methods such as Fourier transform infrared spectroscopy, atomic absorption spectrometry and gas chromatography coupled with mass spectrometry.

\section{EXPERIMENTAL}

\section{A. Materials}

The glucose solution bags used in this study are transparent. These bags are used in hospitals. They were produced by an Italian company which is specialized in the production of flexible containers in PVC. Nitric acid used in the mineralization (purity of 65\%) is purchased from the Spanish company Panreac Quimica Slu and used as received. The dioctyl phthalate (DOP) used in the identification and quantification of the plasticizer in the composition of glucose solution bags formulation is a low volatile substance produced by Société Générale of Tunisia Plasticizers. Tetrahydrofuran and chloroform of high purity HPLC grade were purchased from Panreac Quimica Slu. Sigma Aldrich from Germany produces the methanol used in GC/MS (purity of 99.99\%).

\section{B. Migration Testing and Sample Preparation}

Migration tests were conducted using glucose solution bags, stored in real conditions by respecting the temperatures and the time of conservation. The bags were stored for 18 months (the shelf life of the glucose solution) at temperature between 18 and $22^{\circ} \mathrm{C}$ in the central pharmacy of the hospital which is the usual area for their conservation before their use by different services. To carry out the various analyzes, samples were collected from the bags taken off every three months; they were washed with deionised water and dried at $40^{\circ} \mathrm{C}$. A new bag without contact with glucose solution was taken as a control bag.

\section{Fourier Transform Infrared (FTIR) Spectroscopy Analysis}

The technique applied is Universal Attenuated Total Reflexion (U.A.T.R). Infrared solution software was used for spectra processing data. All spectra were obtained using an ATR-FTIR Spectrum One model infrared spectrometer of PerkinElmer ${ }^{\circledR}$. The spectra were collected at a resolution of $2 \mathrm{~cm}^{-1}$ in the range of $4000-650 \mathrm{~cm}^{-1}$. Each spectrum was rationed against a fresh background spectrum recorded from the bare ATR crystal. Before collection of each background spectrum, the ATR crystal was cleaned with absolute ethanol to remove any residual. Each sample was scanned in triplicate.

\section{Atomic Absorption Spectrometry Analysis}

Before analysis, a mineralization of the samples was performed according to Vandeburg and Clifford [18]. The analysis was carried out with an AAnalyst 800-PerkinElmer ${ }^{\mathbb{B}}$ with Zeeman effect for graphite furnace system and on AAnalyst 300PerkinElemer ${ }^{\mathbb{B}}$ with deuterium lamp for flame system.

\section{E. Gas Chromatography - Mass Spectrometry (GC/MS) Analysis}

For the gas chromatography analysis, the separation of plasticizers from PVC was done by the dissolution/precipitation process $[19,20]$. The dried extract was dissolved in chloroform and analyzed on a Perkin Elmer ${ }^{\circledR}$ GC/MS system, with a medium polarity capillary column $(P E-5 M S$ column $(30 \mathrm{~m} \times$ $0.25 \mathrm{~mm}$ ), with film thickness of $0.25 \mu \mathrm{m})$. Carrier gas was helium with a flow of $1.2 \mathrm{ml} / \mathrm{min}$ and $31 \mathrm{kPa}$ of pressure. One microliter of the sample was injected using splitless injection with injector temperature $300^{\circ} \mathrm{C}$ according to the following conditions: $90^{\circ} \mathrm{C}$ for $3 \mathrm{~min}$ with $6^{\circ} \mathrm{C} / \mathrm{min}$ up to $280^{\circ} \mathrm{C}$, the final temperature was held for $13 \mathrm{~min}$. The total run time for each sample was $48 \mathrm{~min}$.

For mass spectrometry detection, electron ionization with $70 \mathrm{eV}$ was applied and mass fragments were detected between 50 and $450 \mathrm{~m} / \mathrm{z}$. Both the ion source temperature and transfer line temperature were at $280^{\circ} \mathrm{C}$. Note that the detector was activated after $5 \mathrm{~min}$ on mode electronic impact.

The dosage of DEHP in the control bag and in the bags that have undergone the migration test was performed by establishing a calibration curve produced by mixing DOP standard in chloroform at concentrations that covered the concentration range found in the polymer extracts; the resulting 
line was linear with correlation coefficient of 0.998 . Three analytical replicates were analysed for each concentration.

\section{RESULTS AND DISCUSSION}

\section{A. FTIR Investigation of the PVC Films Before and After Migration Testing}

The comparison of the three spectra in Fig. 1 allowed the identification of some characteristic bands which are present in serum bag spectra but don't exist in PVC spectrum; these bands refer to the additives present in the formulation of serum container.

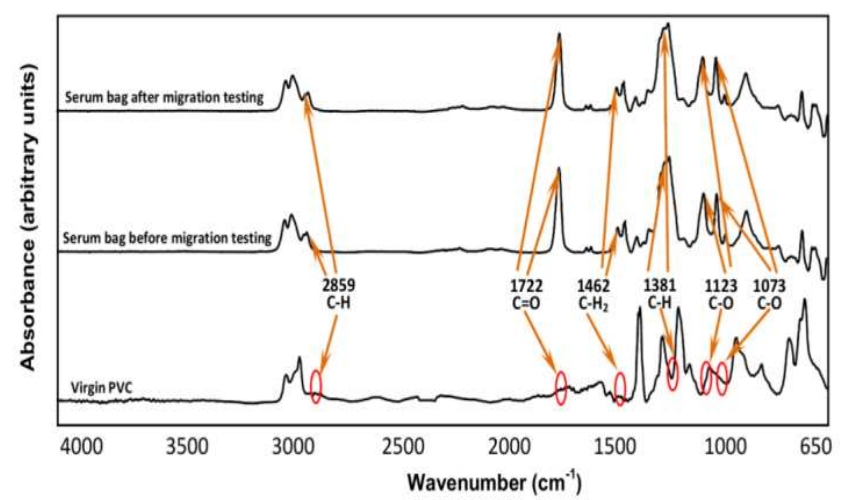

Fig. 1: Infrared spectra of PVC and serum bag before and after migration testing.

The spectra in Fig. 1 show $\mathrm{C}=\mathrm{O}$ (ester) group stretching vibration at $1722 \mathrm{~cm}^{-1}$ and $-\mathrm{CH}$ stretching vibrations at 2859 and $1381 \mathrm{~cm}^{-1}$ [21-24]. The $-\mathrm{C}-\mathrm{O}$ group absorbs at 1123 and $1073 \mathrm{~cm}^{-1}$ while the $-\mathrm{CH}_{2}$ group absorbs at $1462 \mathrm{~cm}^{-1}$, which permits to expect a possible presence of additives such as dioctyl phthalate (DOP) as plasticizer (Fig. 2), zinc stearate as heat stabilizer and a phenol derivative as an antioxidant [25, $26]$.

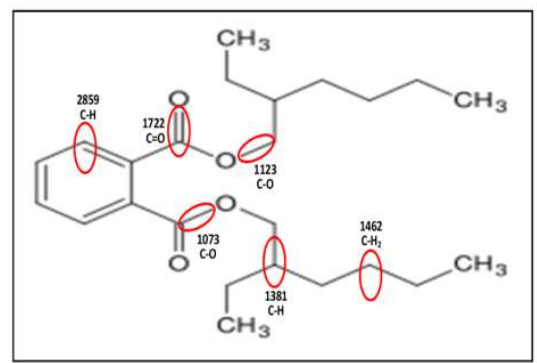

Fig. 2: Molecular structure of di(2-ethylhexyl) phthalate (DEHP).

The study of FTIR spectra of the control bag and bags contacted the glucose solution for various times in months were performed in order to follow the evolution of characteristic additives bands in the formulation of the polymer constituting these bags. The comparison of PVC films spectra (Fig. 3) shows a decrease in all additives bands, especially of the carbonyl band at $1722 \mathrm{~cm}^{-1}$. The ester band at $1722 \mathrm{~cm}^{-1}$ would be associated with the presence of plasticizer from the phthalates family as shown in Fig. 2 -whose presence was confirmed by GC/MS analysis- and thermal stabilizer of the family of epoxidized oils or metallic stearates. Generally, dioctyl phthalate, epoxidized soybean oil and zinc stearate are the most used additives $[25,26]$.

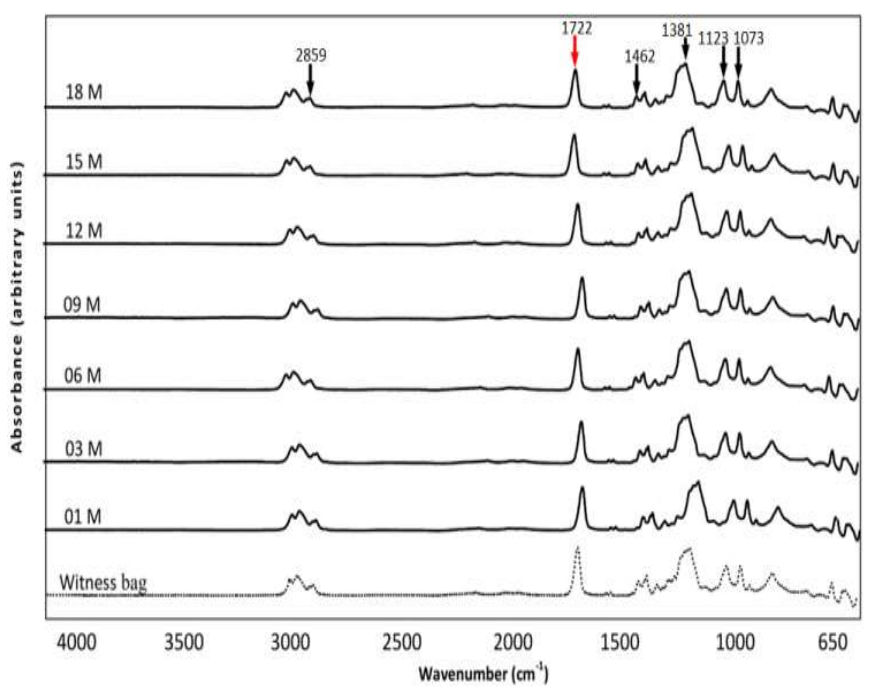

Fig. 3: FTIR spectra of serum bags at different contact time (months).

To study the changes undergone by each band, a semiquantitative estimation was carried out by calculating the following absorbance ratios (Fig. 4): A2859/A1428, A1722/A1428, A1462/A1428, A1381/A1428, A1123/A1428 and A1073/A1428. The band at $1428 \mathrm{~cm}^{-1}$ corresponding to the $\mathrm{CH}_{2}$ bond in PVC is used as a reference band [27].
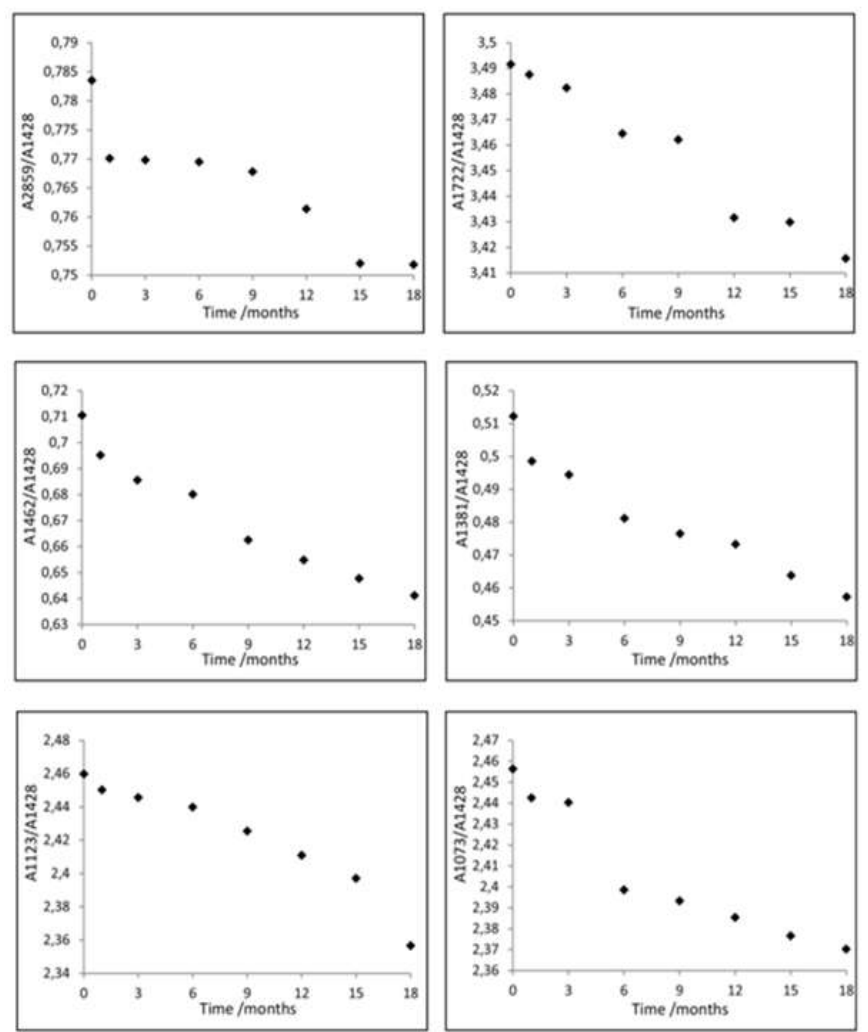

Fig. 4: Absorbance ratio's variation as a function of contact time of serum bags.

According to Fig. 4 gathering the variation of these ratios depending on the contact time, a decrease of all the ratios is observed on all the curves. This indicates that the migration of a certain amount of additives (dioctyl phthalate, zinc stearate, epoxidized soybean oil) present in the poly(vinyl chloride) bag's towards the glucose solution occurred; this phenomenon was already observed in other studies [28-30]. 
The decrease shown in all the curves without the appearance of any increase of the studied bands absorbance ratios (Fig. 4). More precisely at the wave numbers $1123 \mathrm{~cm}^{-1}$ and $1073 \mathrm{~cm}^{-1}$, relative to the vibration of the $-\mathrm{CO}$ band, also found in the infrared spectrum of glucose according to the literature, it can indicate that there is no penetration of glucose molecules because of their large size. This result is also confirmed by the non-appearance of the $-\mathrm{OH}$ band which can be between 3600 $3643 \mathrm{~cm}^{-1}$ in the infrared spectrum of the bag which contained glucose under the migration tests (Fig.1 and Fig. 2) [31].

\section{B. AAS Investigation of the PVC Films Before and After Migration Testing}

The atomic absorption spectrometry was applied to the determination of the metal content in the control bag and in those that have been in contact with the glucose solution for different contact times.
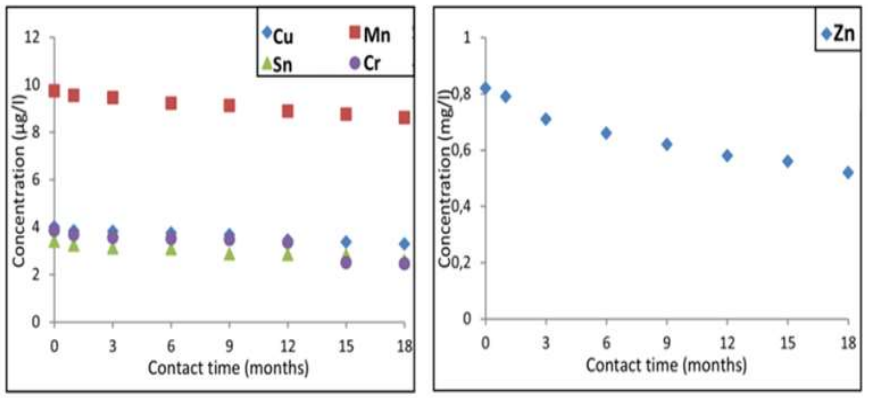

Fig. 5: Variation of the residual content of metals in bags conditioning the glucose solution.

The results obtained show the presence of copper $(\mathrm{Cu})$, chromium $(\mathrm{Cr})$, manganese $(\mathrm{Mn})$, tin $(\mathrm{Sn})$ and zinc $(\mathrm{Zn})$. The presence of the latter is probably due to the zinc stearates, its characteristic bands have also been detected by infrared spectroscopy. The presence of the other elements would be related to the other additives present in the formulation and to the possible impurities they contain.

According to Fig. 5, a decrease in all residual metal's concentration in bags containing the glucose solution through storage time can be observed. This decrease is related to the migration of DEHP, so that creates gaps in the structure of the bags' polymer which involve the migration of other additives like $\mathrm{Zn}$ stearate. The results of atomic absorption spectrometry are in accordance with the results obtained by FTIR spectroscopy.

\section{GC/MS Investigation of the PVC Films Before and After Migration Testing}

\section{Identification of serum bag's plasticizer}

To identify the serum bag's plasticizer, the control bag was analysed by GC/MS method. The identification of the peak was deduced by searching in the MS libraries (NIST) and further confirmed by running the known chemicals for DOP. The identification and quantification of DOP in glucose solution bags were performed using $\mathrm{m} / \mathrm{z} 149$ [27].
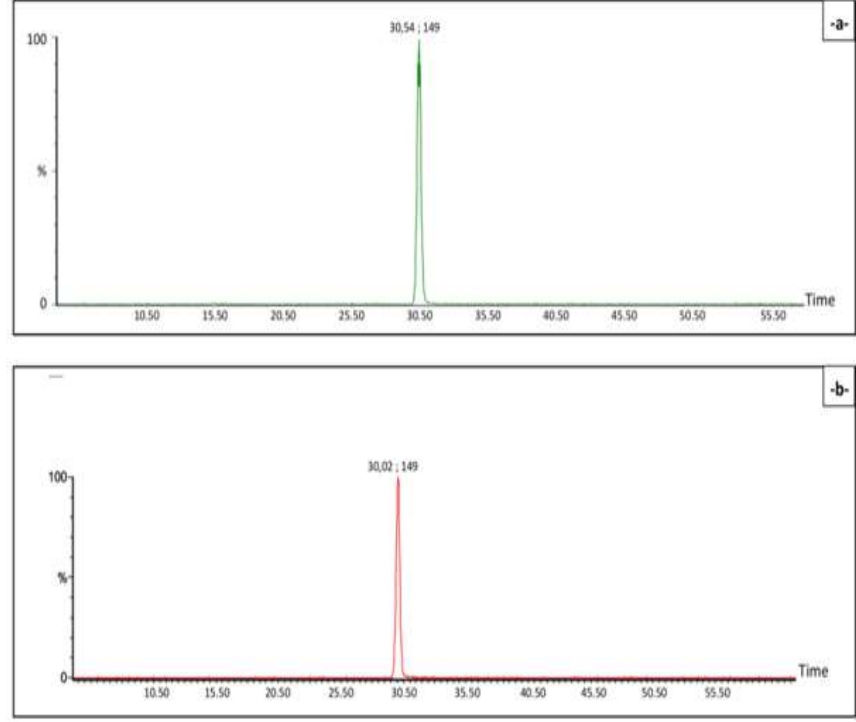

Fig. 6: Chromatogram of: -a- the extract from the serum bag. -b- the DOP standard.

From the chromatogram of the extract of the reference serum bag and of the DOP standard (Fig. 6) analysed by GC/MS in the same operating conditions, the presence of one major peak can be noted. It has a retention time of 30.54 minutes with $\mathrm{m} / \mathrm{z}$ 149 which is practically the same retention time of DOP $(30.02$ min) and which confirms that the plasticizer used in the manufacture of these bags is dioctyl phthalate. It is to be noted that all phthalate plasticizers have a basic characteristic peak at $\mathrm{m} / \mathrm{z}=149$.

These results were confirmed in Fig. 7 which shows the mass spectra of the control bag extract, the DOP standard and of the DEHP spectrum according to the literature. Through these spectra, it can be confirmed that the plasticizer used in the serum bags formulation is the di-2 ethyl hexyl phtalate (DEHP) which is also a ramified dioctyl phthalate.
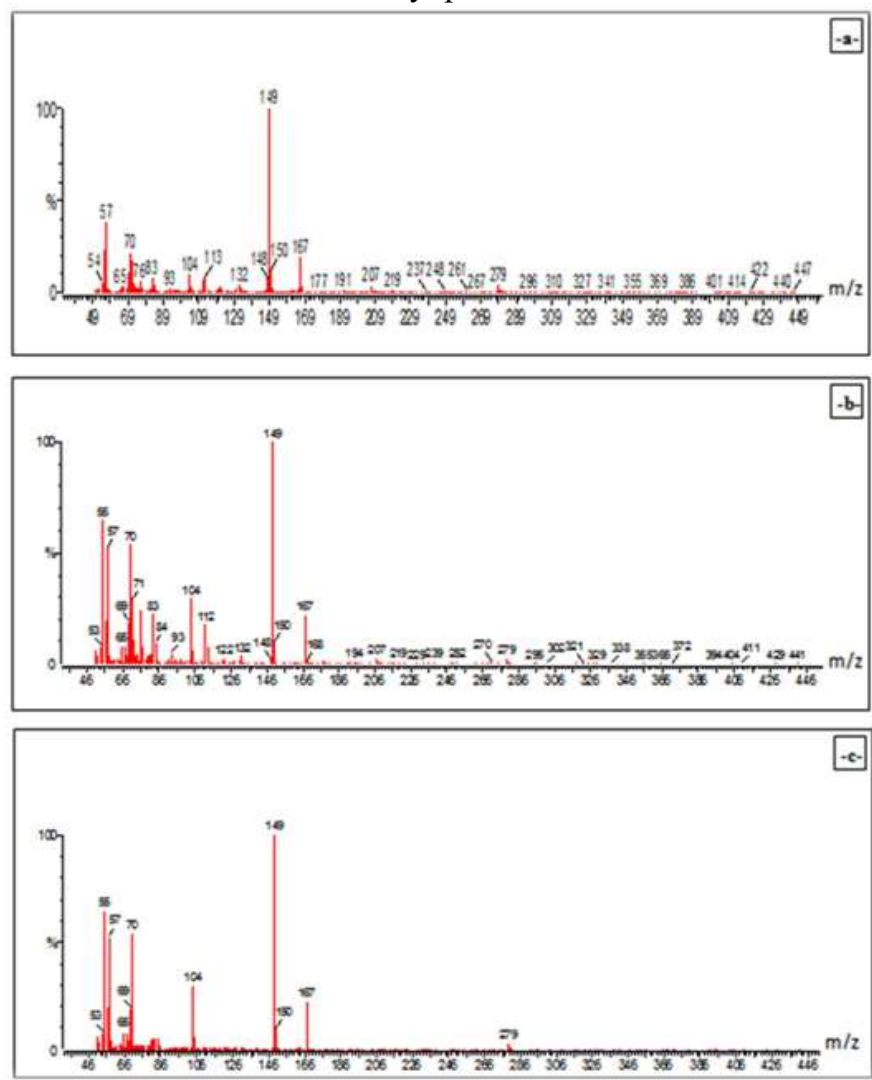

Fig. 7: Mass spectrum of: -a- the extract from control serum bag. -b- the DOP standard. -c- DEHP according to the literature. 
Using the SM peaks of Fig. 7, we can propose the different steps of di (2-ethylhexyl) phthalate defragmentation, which are presented in Fig. 8 [32].

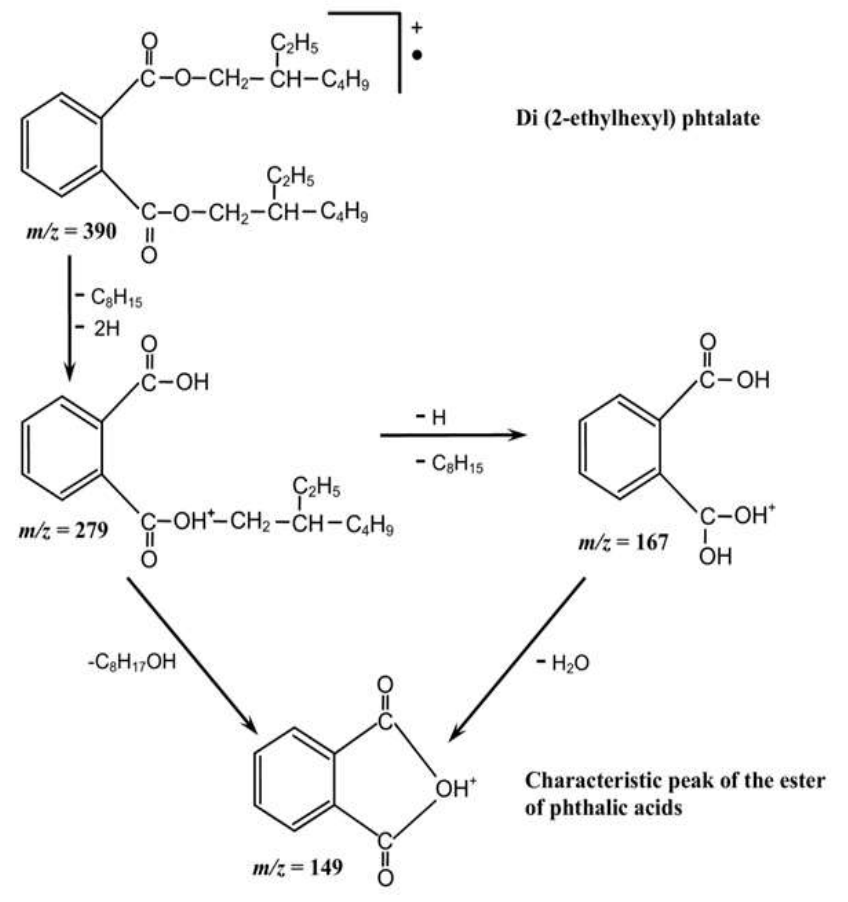

Fig. 8: Defragmentation scheme of DEHP.

\section{Quantification of DEHP in serum bags}

Table. I represents the results of the quantitative gas chromatography analyzes of the control bag and the bags which have undergone the migration tests at the $3^{\text {rd }}, 9^{\text {th }}$ and $18^{\text {th }}$ month of contact.

Table. I

GAS CHROMATOGRAPHY ANALYSIS RESULTS.

\begin{tabular}{lcccc}
\hline \hline- & $\begin{array}{c}\text { Control } \\
\text { bag }\end{array}$ & $\begin{array}{c}\text { Bag stored } \\
\text { for 3 months }\end{array}$ & $\begin{array}{c}\text { Bag stored } \\
\text { for 9 months }\end{array}$ & $\begin{array}{c}\text { Bag stored } \\
\text { for 18 months }\end{array}$ \\
\hline Peak area $(\mu \mathrm{v} / \mathrm{s})$ & 3256553 & 3254456 & 3251739 & 3250261 \\
$\begin{array}{l}\text { Residual [DEHP] } \\
(\mathrm{ppm})\end{array}$ & 2.391 & 2.389 & 2.387 & 2.386 \\
$\begin{array}{l}{[\mathrm{DEHP}] \text { migrated }} \\
(\mathrm{ppm})\end{array}$ & $/$ & 0.002 & 0.004 & 0.005 \\
\begin{tabular}{l} 
\% of leaching \\
\hline \hline
\end{tabular} & $/$ & 0.084 & 0.167 & 0.209 \\
\hline
\end{tabular}

According to Table. I, it appears that the decrease in specific surface DEHP peaks corresponds to the reduction of residual concentrations of this plasticizer in any bag having undergone migration testing, which means the leaching of DEHP in the solution due to the presence of glucose molecule and time contact. The ratio of leaching was about $0.209 \%$ after 18 months of contact.

Several works having studied the influence of time on diffusion of di(2-ethylhexyl) phthalate from PVC into infused drug solutions and human biological fluids were reported [33-37]. Some studies showed a greater concentration of the plasticizer at the surface, resulting in the formation of a more plasticized layer near the interface. In this case the plasticizer can be transferred from the plasticized polyvinyl chloride into the liquid phase by a three steps: (1) plasticizer transport into solid PVC itself, (2) transport phenomena at the interface of PVC and solution, (3) plasticizer transport onto the liquid [38,39]. Fig. 9 shows the evolution of the residual concentration of DEHP in control bag and in those conditioning glucose solutions at various contact times. A low decrease can be observed.

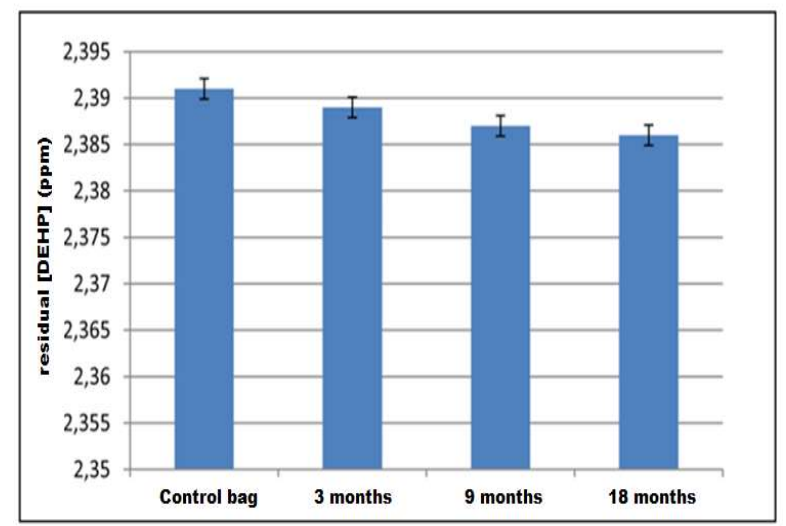

Fig. 9: Comparison of the residual rates of the DEHP in control bag and in those conditioning the glucose solution at different time contact.

\section{IV.CONCLUSION}

Based on the results of this study, the issues to be noted are the following:

The application of the FTIR spectroscopy allowed to confirm that PVC is the constitutive polymer of the glucose bags. This technique allows expecting the presence of plasticizer from the phthalates family, thermal stabilizer of the family of epoxidized oils or metallic stearates. The follow-up of the variation of the characteristic bands of the additives according to the time of contact between the bags and the glucose solution showed that a phenomenon of migration of these additives took place.

The AAS results showed that the PVC bags formulation contains copper, manganese, tin, chromium and zinc. The presence of the latest element is related to the zinc stearate stabiliser. The follow-up of the variation of the residual contents of metals in bags conditioning the glucose solution showed the loss of additives during storage time.

The GC/MS analysis of the control bag and of the bags which were submitted to the tests of migration allowed to confirm that the di(2-ethylhexyl) phthalate (DEHP) is the plasticizer used in the formulation of the serum bag and showed that its migration occurred in glucose solution. The phenomenon is influenced by the time of contact.

\section{ACKNOWLEDGMENT}

Special thanks to Dr. B. Aloui and his team from CRNA (Centre de Recherche Nucléaire d'Alger, Algeria) for performing GC/MS analysis. Also thanks to Dr. N. Larjane (Université Mouloud Mammeri de Tizi Ouzou, Algeria) and Dr R. Mihoub (Centre National de Toxicologie d'Alger, Algeria) for their help in this work.

\section{REFERENCES}

[1] T. D. Stark, H. Choi and P. W. Diebel, "Influence of plasticizer molecular weight on plasticizer retention in PVC geomembranes", Geosynth. Int., vol. 12 , no. 2 , pp. $99-110,2005,10.1680 /$ gein.2005.12.2.99.

[2] E. Testai, P. Hartmann, S. C. Rastogi, U. Bernauer, A. Piersma, W. De Jong and T. Vermeire, "The safety of medical devices containing DEHP plasticized PVC or other plasticizers on neonates and other groups possibly at risk", Regul. Toxicol. Pharmacol., vol. 76, pp. 209-210, 2016 , 10.1016/j.yrtph.2016.01.013 
[3] A. Arthur and M. D. Strauss, "Di(2-ethylhexyl)phthalate (DEHP)", $J$. Pediatr. Pharmacol. Ther., vol. 9, no. 2, pp. 89-95, Apr. 2004, 10.5863/1551-6776-9.2.89.

[4] H. Y. Kim, "Risk assessment of di(2-ethylhexyl) phthalate in the workplace", Environ. Health. Toxicol., vol. 31, May. 2016, 10.5620/eht.e2016011.

[5] Y. Xu, T. J. Cook and G. T. Knipp, "Effects of di-(2-ethylhexyl)phthalate and its metabolites on fatty acid homeostasis regulating proteins in rat placental HRP-1 trophoblast cells", Toxicol. Sci., vol. 84, pp. 287-300, Jan. 2005, 10.1093/toxsci/kfi083.

[6] S. H. Abdel-Kawi, K. S. Hashem and S. Abd-Allah, "Mechanism of diethylhexyl phthalate (DEHP) induced testicular damage and of grape seed extract-induced protection in the rat", Food. Chem. Toxicol., vol. 90, pp. 64-75, Apr. 2016, 10.1016/j.fct.2016.02.003.

[7] B. Van Ravenzwaay, G. Coelho-Palermo Cunha, V. Strauss, J. Wiemer, E. Leibold, H. Kamp, T. Walk, W. Mellert, R. Looser, A. Prokoudine, E. Fabian, G. Krennrich and M. Herold, "The individual and combined metabolite profiles (metabolomics) of dibutylphthalate and di(2ethylhexyl)phthalate following a 28-day dietary exposure in rats", Toxicol. Lett., vol. 198, no. 2, pp. 159-170, Oct. 2010, 10.1016/j.toxlet.2010.06.009

[8] N. Y. Kim, T. H. Kim, E. Lee, N. Patra, J. Lee, M. O. Shin, S. J. Kwack, K. L. Park, S. Y. Han, T. S. Kang, S. H. Kim, B. M. Lee and H. S. Kim, "Functional role of phospholipase D (PLD) in di(2-ethylhexyl) phthalate-induced hepatotoxicity in sprague-dawley rats", J. Toxicol. Environ. Health., vol. 73, pp. 1560-1569, Oct. 2010, $10.1080 / 15287394.2010 .511582$.

[9] P. Erkekoglu, N. D. Zeybek, B. K. Giray, W. Rachidi, M. Kizilgün, I. Hininger-Favier, A. Favier, E. Asan and F. Hincal, "The effects of di(2ethylhexyl) phthalate on rat liver in relation to selenium status", Int. J. Exp. Pathol., vol. 95, no. 1, pp. 64-77, Nov. 2014, 10.1111/iep.12059.

[10] X. F. Huang, Y. Li, Y. H. Gu, M. Liu, Y. Xu, Y. Yuan, F. Sun, H. Q. Zhang and H. J. Shi, "The effects of di-(2-ethylhexyl)-phthalate exposure on fertilization and embryonic development in vitro and testicular genomic mutation in vivo", PLoS ONE, vol. 7, no. 11, Nov. 2012, 10.1371/journal.pone.0050465.

[11] E. G. Radke, J. M. Braun, J. D. Meeker and G. S. Cooper, "Phthalate exposure and male reproductive outcomes: A systematic review of the human epidemiological evidence", Environ. Int., vol. 121, pp. 764-793, Oct. 2018, 10.1016/j.envint.2018.07.029.

[12] W. Kessler, W. Numtip, W. Völkel, E. Seckin, G, A. Csanády, C. Pütz, D. Klein, H. Fromme and J. G. Filser, "Kinetics of di(2-ethylhexyl) phthalate (DEHP) and mono (2-ethylhexyl) phthalate in blood and of DEHP metabolites in urine of male volunteers after single ingestion of ring-deuterated DEHP”. Toxicol. Appl. Pharmacol., vol. 264, no. 2, pp. 284-291, Aug. 2012, 10.1016/j.taap.2012.08.009.

[13] A. Hartwig and MAK Commission, "Di(2-ethylhexyl) phthalate (DEHP) [MAK Value Documentation, 2015]”, vol. 1, no. 3, pp. 1743-1791, Jul. 2016, 10.1002/3527600418.mb11781e5916.

[14] J. A. Tickner, T. Schettler, T. Guidotti, M. McCally and M. Rossi, "Health risks posed by use of di-2-ethylhexyl phthalate (DEHP) in PVC medical devices: a critical review", Am. J. Ind. Med., vol. 39, no. 1, pp. 100-111, Jan. 2001, 10.1002/1097-0274(200101)39:1<100::aidajim10>3.0.co;2-q.

[15] Y. Haishima, T. Kawakami, C. Fukui, A. Tanoue, T. Yuba, S. Ozono, H. Kumada, K. Inoue, T. Morikawa, M. Takahashi, A. Fujisawa, K. Yamasaki, Y. Nomura, K. Isama, U. Chung, K. Ogawa, Shingo Niimi and M. Yoshida, "Characterization of alternative plasticizers in poly(vinyl chloride) sheets for blood containers", J. Vinyl. Addit. Technol., vol. 22, no. 4, pp. 520-528, Dec. 2016, 10.1002/vnl.21472.

[16] H. Miao, H. Zhao and P. Jiang, "Poly(vinyl chloride) films plasticized with novel poly-nadic-anhydride polyester plasticizers", J. Vinyl. Addit. Technol., vol. 23, no. 4, pp. 321-328, Aug. 2015, 10.1002/vnl.21510.

[17] H. M. Koch, H. Drexler and J. Angerer, "An estimation of the daily intake of di(2-ethylhexyl)phthalate (DEHP) and other phthalates in the general population", Int. J. of Hyg. Environ. Health, vol. 206, no. 2, pp. 77-83, 2003, 10.1078/1438-4639-00205.

[18] H. J. Vandeburg, A. A. Clifford, K. D. Bartle, J. Carroll, I. Newton, L. M. Garden, J. R. Dean and C. T. Costley, "Analytical extraction of addives from polymers", Analyst, vol. 122, no. 9, pp. 101R-115R, Sept. 1997, 10.1039/A704052K.
[19] H. J. Vandeburg, A. A. Clifford, K. D. Bartle, J. Carroll, I. Newton, L. M. Garden, J. R. Dean and C. T. Costley, "Analytical extraction of addives from polymers", Analyst, vol. 122, no. 9, pp. 101R-115R, Sept. 1997, 10.1039/A704052K.

[20] Q. Wang and B. K. Storm, "Separation and analysis of low molecular weight plasticizers in poly(vinyl chloride) tubes", Polym. Test., vol. 24, no. 3 , pp. 290-300, Jan. 2005, 10.1016/j.polymertesting.2004.12.002.

[21] L. Fantoni and C. Simoneau, "European survey of contamination of homogenized baby food by epoxidized soybean oil migration from plasticized PVC gaskets", Food. Addit. Contam., vol. 20, no. 11, pp. 1087-1096, Nov. 2003, 10.1080/02652030310001615186.

[22] F. N. Ajjan, M. J. Jafari, T. Rębis, T. Ederth and O. Inganãs, "Spectroelectrochemical investigation of redox states in a polypyrrole/lignin composite electrode material", J. Mater. Chem. A, vol. 3, no. 24, pp. 12927-12937, May. 2015, 10.1039/c5ta00788g.

[23] M. D Guillén and N. Cabo, "Infrared spectoscopy in the study of edible ails and fats", J. Sci. Food. Agric., vol. 75, no. 1, pp.1-11, 1997 10.1002/(SICI)1097-0010(199709)75:1<1::AID-JSFA842>3.0.CO;2$\mathrm{R}$.

[24] M. Beltrán, and A. Marcilla, "PVC plastisols de composition by FT-IR spectroscopy”, Eur. Polym. J., vol. 33, no. 8, pp. 1271-1280, Aug. 1997, 10.1016/S0014-3057(97)00004-9.

[25] H. Baltacioğlu and D. Balköse, "Effect of zinc stearate and/ epoxidized soybean oil on gelation and thermal stability of PVC-DOP plastigels", $J$. Appl. Polym. Sci., vol. 74, no. 10, pp. 2488-2498, Sept. 1999, 10.1002/(SICI)1097-4628(19991205)74:10<2488::AID-

APP18>3.0.CO;2-B.

[26] M. A. Semsarzadeh, M. Mehrabadeh and S. S. Arabshahi, “ Dynamic mechanical behavior of the diocty phthalate plasticized polyvinyl chloride-epoxidized soya bean oil", Eur. Polym. J., vol. 38, no. 2, pp. 351-358, Oct. 2002, 10.1016/S0014-3057(01)00168-9.

[27] M. O. Boussoum and N. Belhaneche-Bensemra, "Study and optimization of soaking treatment to reduce migration from plasticized polyvinyl chloride", J. Appl. Polym. Sci., vo.124, no. 2, pp. 1241-1248, Oct. 2011, 10.1002/app.35141.

[28] D. Atek and N. Belhaneche-Bensemra, "FTIR investigation of the specific migartion of addives from rigid poly(vinyl chloride) ", Eur. Polym. J., vol. 41, no. 4, pp. 707-714, Jan. 2005, 10.1016/j.eurpolymj.2004.10.043.

[29] T. J. Suhrhoff and B. M. Scholz-Böttcher, "Qualitative impact of salinity, UV radiation and turbulence on leaching of organic plastic additives from four common plastics- A lab experiment", Mar. pollut. bull., vol. 102, no. 1, pp. 84-94, Jan. 2016, 10.1016/j.marpolbul.2015.11.054.

[30] D. Ikermoud, H. Benaissa, W. Kherfane and N. Belhaneche-Bensemra "Investigation of additives migration from salted serum bags", Polym. $\begin{array}{lllll}\text { Test., } & \text { vol. } & \text { 80, }\end{array}$ 10.1016/j.polymertesting.2019.106118.

[31] L. J. Bellamy, "Alcohols and phenols" in The infra-red spectra of complex molecules, $3^{\text {rd }}$ ed. Ed. Chapman and Hall, London, UK, 1975 , pp. 107-128, 10.1007/978-94-011-6017-9.

[32] A. O. Earls, I. P. Axford and J. H. Braybrook, "Gas chromatographymass spectrometry determination of the migration of phthalate plasticisers from polyvinyl chloride toys and childcare articles", $J$. chrom. A, vol. 983, pp. 237-246, Jan. 2003, 10.1016/s00219673(02)01736-3.

[33] J. Kastner, D. G. Cooper, M. Marić, P. Dodd and V. Yargeau, “Aqueous leaching of di-2-ethyl phthalate and green plasticizers from poly(vinyl chloride)", Sci. Total. Environ., vol. 432, pp. 357-364, 2012, 10.1016/j.scitotenv.2012.06.014.

[34] L. Bernard, B. Décaudin, M. Lecoeur, D. Richard, D. Bourdeaux, R. Cueff, V. Sautou, "Analytical methods for the determination of DEHP plasticizer alternatives present in medical devices: A review", Talanta., vol. 129, pp. 39-54, 2014, 10.1016/j.talanta.2014.04.069.

[35] J. R. Snell, C. R. Monticello, C. Her, E. L. Ross, A. A. Frazer-Abel, J. F. Carpenter and T. W. Randolph, "DEHP nanodroplets leached from polyvinyl chloride IV bags promote aggregation of IVIG and activate complement in human serum", J. Pharm. Sci., vol. xxx, pp. 1-14, 2019 , 10.1016/j.xphs.2019.06.015. 
[36] J. L.Taverdet and J. M. Vergnaud, "Modelisation of matter transfers between plasticized PVC and liquids in case of a maximum for liquidtime curves", J. Appl. Polym. Sci., vol. 31, pp. 111-122, 1986, 10.1002/app.1986.070310111.

[37] E. Testai, P. Hartemann, S. C. Rastogi, U. Bernauer, A. Piersma, W. De Jong, H. Gulliksson, R. Sharpe, D. Schubert, E. Rodriguez-Farre and Ms Scientific Committee SCENIHR, "The safety of medical devices containing DEHP plasticized PVC or other plasticizers on neonates and other groups possibly at risk (2015 up date)", Regul. Toxicol. Pharmacol., vol. 76, pp. 209-210, 2016, 10.1016/j.yrtph.2016.01.013.

[38] H. Al Salloum, J. Saunier, A. Tfayli and N. Yagoubi, "Studying DEHP migration in plasticized PVC used for blood bags by coupling Raman confocal microscopy to UV spectroscopy", Mat. Sci. Eng., vol. 61, pp.56-62, 2016, 10.1016/j.msec.2015.12.008.

[39] D. Messadi, J. M. Vergnaud and M. Hivert, "A new approach to the study of plasticizer migration from PVC into methanol", J. Appl. Polym. Sci., vol. 26, pp. 667-677, 1981, 10.1002/app.1981.070260225.

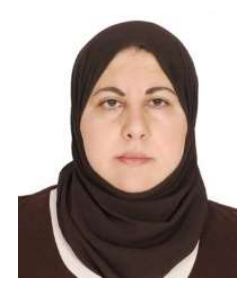

Dalila Ikermoud has received her State Engineer degree in Industrial Chemistry with "Environment" option from Saâd Dahlab University (Blida-Algeria) in 1999, her Magister degree and $\mathrm{PhD}$ degree in Environmental Engineering both from Ecole Nationale Polytechnique (Algiers-Algeria) in 2010 and 2020, respectively. From 2003 until 2016, she was with the Centre National de Toxicologie (Algiers-Algeria) as a Chemical Engineer. Since 2016, she is with the Centre de Recherche en Technologie des SemiConducteur (CRTSE) (Algiers-Algeria).

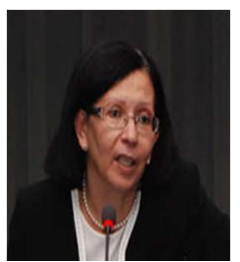

Naima Belhaneche-Bensemra is professor at the Environmental Engineering Department of the Ecole Nationale Polytechnque, Algiers. She is Head of the Materials and Environment Interactions Team at the Laboratory of Sciences and Techniques of the Environment since 2000. She received the Engineering Degree in Chemical Engineering in 1985 from university Ferhat Abbas of Sétif(Algeria) and the $\mathrm{PhD}$ Degree in Polymeric Materials and Composites from university Claude Bernard-Lyon I (France) in 1989. She is author and co-author of about 110 publications in peer reviewed high impact factor journals as well as 11 invited book chapters. She is in the editorial boards of several journals and referee of about 40 journals. Her research interests focus on oil based and bio derived polymers and composites; polymer blends; ageing, degradation, stabilization and recycling of polymers; valorization of renewable resources; interactions in plastics food packaging.

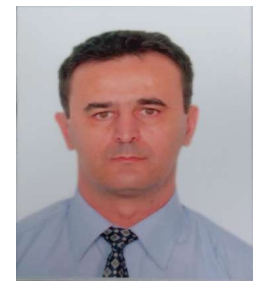

Hicham Benaissa is a Chief engineer at the Central Forensic Laboratory of Algiers, where he is in charge of analytical instrumentation using optical and chromatographic techniques with analysis covering a wide range of crime clues like drugs, toxics, explosives, hazardous materials. He has cooperated several times with universities in both technical assistance and supervision of students preparing Master and PhD degrees. Prior to joining Central Forensic LabAlgiers, Hicham Benaissa has teached chemistry in high school from 1990 to 1996 in full time and at USTHB university as an analytic Lab teacher-assistant by time. Hicham Benaissa was born in 1966 and raised in Algiers city. He obtained in 1990 his State Engineer Degree in Chemical Engineering from Ecole Nationale Polytechnique and the Post Graduate Diploma in instrumental Methods of identification and characterization in 2008 from USTHB. In addition he obtained the advanced level in English in 2017 at the Intensive Language Learning Centre of Algiers University and recently he received a Master degree in Nuclear Security from USTHB in 2020. 